\title{
CPEC- AN ECONOMIC ENGINE FOR PEACE AND ITS IMPACT ON KASHMIR DISAGREEMENT
}

\author{
Fakhar Hussain $^{1 *}$, Muhammad Ikramullah Khan ${ }^{2}$, Sarfraz Hussain $^{3}$, Saadat Nawaz $^{4}$ \\ ${ }^{1 *}$ Lecturer in Civics at Government Imamia Associate College, Sahiwal, Pakistan; ${ }^{2}$ Assistant Professor, The Islamia \\ University of Bahawalpur, Pakistan; ${ }^{3}$ Assistant Professor (Commerce), Government Graduate College, Liaqat Road, \\ Sahiwal, Pakistan; ${ }^{4}$ Visiting Lecturer, University of Sahiwal, Pakistan. \\ Email: ${ }^{1 *}$ diplomat786@gmail.com, ${ }^{2}$ m.ikramullah@iub.edu.pk, ${ }^{3}$ mianfraz1@gmail.com, ${ }^{4}$ raisaadat182@gmail.com
}

Article History: Received on $21^{\text {st }}$ May 2021, Revised on $29^{\text {th }}$ May 2021, Published on $5^{\text {th }}$ June 2021

\section{Abstract}

Purpose of the study: This research explores CPEC as a model of "Economic Interdependence" for being a mega driver of Globalization, which can bring economic equilibrium through development and interconnectivity for resolution of Kashmir dispute by connecting institutional and diplomatic channels to the economic interdependency.

Methodology: This research is based on secondary data collected from various sources like academic papers, electronic sources, Newspapers, Periodicals, Journals, organizational reports, and books. For interpretation of data, descriptive and analytical approach has to be adopted by using the deductive method of investigation.

Principal Findings: The main findings indicate that CPEC will provide grounds for minimizing conflicts on accounts of consistent regional and intra-regional economic connectivity. CPEC will transfigure the geographic position of Azad Jammu and Kashmir into an asset to be an economic engine for the establishment of peace in the region by amicable resolution of prolonged Kashmir dispute using economic connectivity.

Applications of this study: This research will be helpful for academics of peace and conflict studies, International Relations, diplomacy and strategic management, policymakers, diplomats of Pakistan, China, and India. It will contribute to the resolution of the Kashmir dispute.

Novelty/Originality of this study: The novelty/originality of this research lies in the attempt to correlate the concepts of "CPEC as an actor of economic interdependence" and "CPEC as a catalyst for the amicable resolution of Kashmir dispute."

Keywords: Belt and Road Initiative, Regional Connectivity, Silk Route, Economic Interdependence, Globalization, Spill Over.

\section{INTRODUCTION}

In contemporary world affairs, an "economic corridor" includes access to trade resources for the people of connected states to create innovative possibilities for economic endeavours as international trade entities, increasing their mutual importance (Wani, 2017), and that it will transform the individual dependence of nations into interdependence. This model of "Economic Interdependence" was initially conceptualized by US Economist Richard Newell Cooper, which was hitherto modified by Joseph Nye and Robert Cohan in IR, who opined that nation-states are tied conjointly by economic interdependence (Rasool \& Kundi, 2018). CPEC (China-Pak Economic Corridor) is deliberated as an upshot of enduring relationships between Pakistan and China (Bhattacharjee, 2015). It is an umbrella venture proposed under the "One Belt, One Road" enterprise of China (Markey \& West, 2016). In Asia, the two emerging economies, China and Pakistan, conjointly have endeavoured to formulate an "Economic Corridor" known to be CPEC to accomplish their economic objectives for mutual growth and development (Wani, 2017). It is believed to be a landmark joint venture marking a novel era of geostrategic and commercial collaboration among the two "all-weather" friends (Bhattacharjee, 2015).

CPEC is the mega driver of Globalization and the instrument of soft balancing and can bring economic equilibrium through development and interconnectivity to bridge parity in soft power between India and Pakistan, which has been a mega impediment for establishing peace in the region (Rasool \& Kundi, 2018). CPEC, as an enormous development project of US\$ 62 billion by China's Silk Road Fund (Hussain \& Hussain, 2017), has been hailed to be a "game-changer" amid China and Pakistan in the geopolitical realities of the region of South Asia (Naseer, 2017). CPEC is considered one of the world's biggest initiatives meant for endorsing regional connectivity and providing funds for financing the development of infrastructure (Baruah, 2018). Economic integration (CPEC) is an effective way to balance the South Asian region between China's two neighbouring nuclear powers, beneficial for all Pakistan and India. (Wellens, 1990).

Geopolitics academics must also have a pragmatic approach, considering that the CPEC will provide trilateral benefits to India, China, and Pakistan (Rifat \& Mini, 2016), which is an international economic benefit lifting and testifying to its framework. China uses Pakistan to understand its interdependence and its implications to maintain the regional balance of power in South Asia and bridge the gap between India and Pakistan (Rasool and Kundi, 2018). There is no ambiguity that conflicts exist between Pakistan and India. Still, the engagement of the people in commercial activities and development from both sides will play a role in minimizing friction in the region to the extent that stakeholders may envision establishing regional peace (Wani, 2017). 
The regional connectivity in the shape of CPEC carries economic leverage to bring a quantum of parity between India and Pakistan, bringing forth chance as a potent catalyst to address the Kashmir issue. The degree of interdependency will have multi-dimensional spillover effects if OBOR is extended and developed in Azad Jammu and Kashmir (Rasool \& Kundi, 2018). The Continent of Asia has an enormous and increasing requirement for the development of infrastructure. There are incredible prospects for cross-border collaboration concerning regional connectivity and infrastructural developments (Baruah, 2018). China has played a significant role in creating a "new world order" built on equivalent prospects for all (Durrani, Bilal, \& Kalim, 2017). Chinese strategy concerning the revitalization of the ancient "Silk Route" is an aspiring concept built on multifaceted collaboration (Hussain, Hussain, Ahmad, Quddus, Rafiq, \& Tien, 2021). This initiative encompasses two components. Firstly, a terrestrial route or an economic belt inter-connecting China with Europeans through the South and Central Asian states. Secondly, the Maritime Silk Route (MSR) intends to create a marine corridor between China and European countries (Baruah, 2018).

It is imperative to interweave the gap in peacemaking by demanding a balance of power. In this way, the CPEC, due to its international connectivity, could be an opportunity to break the imbalance in the South Asian region, given the tremendous potential for economic growth and influence in the regional framework (Rasool \& Kundi, 2018). CPEC may offer innumerable prospects for Pakistan and other regional states; evolving dynamics can minimize or enlarge these opportunities ( $\mathrm{Jia}, 2017)$. It could produce novel equilibrium in economic terms. Pakistan will have to put specific responsibilities entirely upon stakeholders, irrespective of foes or friends, to formulate international and regional strategies pushing towards arrangement for resolving the Kashmir dispute by connecting institutional and diplomatic channels to the economic interdependency (Rasool \& Kundi, 2018). CPEC as a flagship project of OBOR is of enormous prominence for both Pakistan and China (Hussain \& Hussain, 2017). It has been seen as advantageous to China, Pakistan, and India as well as for the whole region and trans-region (Rifaat \& Maini, 2016).

Since the 1947 independence of Pakistan and India, the Kashmir dispute has remained a bone of contention amid India and Pakistan. Three wars have been fought so far between Pakistan and India on Kashmir conflict and keep on being a primary source of irritation in their bilateral relationship. Moreover, it (Kashmir) is also considered a nuclear flashpoint in South Asia between the two significant atomic powers of the region (Dhall, 2018). China has been dealing Kashmir dispute within the framework of the South Asian security dilemma and keeping in view Indian considerations. China's stance over a disagreement of Kashmir remained consistent for supporting Pakistan's viewpoint, but China has never adopted a clear-cut standpoint concerning gross violations of human rights in Kashmir. China supports Pakistan's position in the United Nations, but (China) has not put pressure on a viable solution to the Kashmir issue, hurting India (Rasool \& Kundi, 2018). The dispute of Kashmir remains to be unsettled for the last 73 years of history, which now has become an unstable atomic flashpoint of South Asia in the world. As a result of the extensive damage of human life either because of three significant wars battled amid India and Pakistan or due to Kashmiri's struggle for freedom, the conflict of Kashmir has been carrying severe ramifications of security predominantly for both India and Pakistan (Ali \& Saeed, 2019).

China emerged as a third party to the Kashmir dispute in 1963 by signing a borderline agreement with Pakistan. China has been defending Pakistan's stated position concerning the Kashmir dispute at numerous times that (Kashmir) issue to be resolved by the desires and demands of the people of Kashmir (Rasool \& Kundi, 2018). The formation of tranquillity and safekeeping in the South Asian region is conditioned with the Indo-Pak productive role (Hussain, Ahmad, Nawaz, Haider, \& Atif, 2021). The interlinking of Srinagar to CPEC may not indent India's interests, and in this way, it ought to be a catalyst to boost the Indian economy in case of joining CPEC as a mega driver of economic interdependence in the region. Whether India joins CPEC or endures detachment, the due process of Globalization could not be terminated by India one-sidedly when China's mega economy remains to be on board (Rasool \& Kundi, 2018).

CPEC is viewed as a win-win for India, Pakistan, and China, and the whole region (Hussain, Khan, Hussain, Nawaz, \& Ahmad, 2021). For this study, the international economic benefit and its use have been put into practice in the given circumstances of Kashmir so that peace can be achieved with the distinction that the CPEC will meet the South Asian balance, which is a prerequisite. At the same time, there is minimal scope for economic autonomy alone (Rasool \& Kundi, 2018). A durable economic and humanoid collaboration between the nations in the future has been a source of power for countries (Wani, 2017). This research paper suggests that it leads to a logical sequence, where the whole state of $\mathrm{J}$ and $\mathrm{K}$ from both sides of the LOC is to be declared as 'free economic zone in five phases', keeping the speedy driver of Globalization in the shape of OBOR in consideration. It will be a mega Kashmir centric CBM and a significant catalyst of conflict resolution and establishment of peace in the region (Rasool \& Kundi, 2018). The economic correlation of China with Pakistan and India is crucial concerning the dynamics of regional geopolitics. It may be up to Pakistan and India to reorientate their considerations to be more peaceable pursuits where disputes are minimized and fiscal advantages to be multiplied (Siddiqi, 2018).

\section{The objective of the study}

To explores CPEC as a model of "Economic Interdependence" for being a mega driver of Globalization, which can bring economic equilibrium through development and interconnectivity for resolution of Kashmir dispute by connecting institutional and diplomatic channels to the economic interdependency. 


\section{REVIEW OF LITERATURE}

Rasool and Kundi (2018) analyzed that CPEC is the mega driver of Globalization and an instrument of soft balancing and can bring economic equilibrium through development and interconnectivity to bridge parity in soft power between India and Pakistan, which has been a mega impediment for the establishment of peace in the region. It is imperative to interweave the gap in peacemaking by demanding a balance of power. In this way, the CPEC, due to its international connectivity, could be an opportunity to break the imbalance in the South Asian region, with tremendous potential for economic growth and influence in the regional framework. The regional connectivity in the shape of CPEC carries financial leverage to bring quantum of parity between India and Pakistan, bringing forth chance as a potent catalyst to address the Kashmir issue. The degree of interdependency will have multi-dimensional spillover effects if OBOR is extended and developed in Azad Jammu and Kashmir (Rasool \& Kundi, 2018).

Fatima, Baig, \& Ali Shah (2019) investigated that the impact of the CPEC's splurge would extend from South Asian states to CARs, European states, and the Middle East region, calling a new wave of Globalization in the form of economic interdependence a soft power. For being two strategic actors of the area and other 42 countries of the world, China and Pakistan will also be interconnected through CPEC to become beneficiaries of Beijing's OBOR initiative, based on which the weak actors may seek interdependence in terms of economy. To attain objectives of political, economic, and strategic interests, countries like Afghanistan, Iran, Turkey, Russia, and the CARs also desire to become stakeholders of the CPEC venture. CPEC will redesign the dominant mode of political and economic correlation among different regional states based on economic interconnectivity between CARs, the Middle East, and African countries. Pakistan is pursuing the principle of economic dispersion and desires for embracing a comprehensive approach for economic growth and distribution of the dividends of the CPEC project to numerous states as being stakeholders, which will transform this region to be a novel commercial pivot of the contemporary world (Fatima, Baig, \& Ali Shah, 2019).

Economically, regional integration (CPEC) is considered an effective tool for balancing the three neighboring nuclear powers of China, Pakistan, and India in the South Asian region where it (CPEC) has proved beneficial for everyone (Wellens, 1990).

Iqbal examined that CPEC can promote economic cooperation and interdependence in the region to facilitate the resolution of the Kashmir dispute between Pakistan and India and turn away from zero-sum methodologies of the regional conflicts. It may also pave the ways for the amicable resolution of the prolonged Kashmir dispute using economic connectivity. CPEC is a part of China's six corridors projected under BRI, to be considered an imperative prospect that may bridge the strategic fault-lines by enhancing economic interdependence and regional connectivity between Pakistan and India for being two leading nations of South Asia. CPEC will transfigure the geographic position of Azad Jammu and Kashmir into an asset to be an economic engine for the establishment of peace in the region (Iqbal, $\underline{2018)}$.

\section{CPEC- An Economic Engine}

CPEC is perceived to be the Marshall-Plan version of Beijing in the region (Iqbal, 2018). China has envisioned utilizing the BRI in the accurate spirit of reciprocated growth and regional development (Humayun, 2018). In the context of broader investments for China, Pakistan, and other countries in the region, it should be part of OBOR. It will also be sufficient for land-locked CARs (Hussain, Rafiq, Quddus, Ahmad, \& Tien, 2021). Through this strategic vision of regional connectivity by Beijing, trading and commercial activities could bring development, economic progression, and prosperity to CARs that hitherto remained closed-economies. CPEC will connect CARs to emergent economies of the world through investment ventures by China and the involvement of various stakeholders. The New Silk-Route is linked to the novel concept of expanding "Global Village" (Fatima, Baig, \& Ali Shah, 2019). Xi Jinping, President of China, introduced the SREB (Silk-Road-Economic-Belt) and the $21^{\text {st }}$ century MSR (Maritime-Silk-Road) shared ventures in 2013 (Hussain, Rafiq, Quddus, Ahmad, \& Tien, 2021). China's BRI (Belt and Road Initiative) will comprise almost 60 countries having a population of more than 4.4 billion conjointly (Humayun, 2018).

CPEC is a part of China's six corridors projected under BRI, to be considered an imperative prospect that may bridge the strategic fault-lines by enhancing economic interdependence and regional connectivity between Pakistan and India for being two leading nations of South Asia (Iqbal, 2018). The additional effects of the CPEC will extend from the South Asian states to the CARs, the European states, and the Middle East region, signalling a new wave of Globalization in economic interdependence (Fatima, Baig, \& Ali Shah, 2019). CPEC, under the intensifying dynamics of regional geopolitics, will make available unbound opportunities for steering economic collaboration in South Asia through interlinkages of economies (Siddiqi, 2018). For being two strategic actors of the region and other 42 countries, China and Pakistan will also be interconnected through CPEC to become beneficiaries of Beijing's OBOR initiative. The weak actors may seek interdependence in terms of the economy. To attain political, economic, and strategic objectives, countries like Afghanistan, Iran, Turkey, Russia, and the CARs also desire to become stakeholders of the CPEC venture (Fatima, Baig, \& Ali Shah, 2019).

The concentration of global politics has been shifting from the West towards Asia due to China's substantial role in the continuing antagonism on the chessboard of international politics. The shifting embryonic paradigm of the region will challenge the status quo showing a strategic change with severe ramifications for Pakistan in the evolving security trends 
in South Asia (Hussain, Khan, Hussain, Nawaz, \& Ahmad, 2021). On the one hand, the effects of Globalization using economic interdependence and the increase in economic connectivity through the CPEC effort indicate that it (CPEC) is responsible for trade relations and financial markets in different regions. It will work for the promotion of trade relations (Fatima, Baig, \& Ali Shah, 2019). The China-Pakistan Economic Corridor will provide grounds for minimizing conflicts on accounts of consistent regional and intra-regional economic connectivity in South Asia (Siddiqi, 2018).

CPEC will redesign the dominant mode of political and economic correlation among different regional states based on economic interconnectivity between CARs, the Middle East, and African countries (Fatima, Baig, \& Ali Shah, 2019). CPEC venture envisions regions that may have progressive economic effects on India, Afghanistan, Iran, and the CARs (Siddiqi, 2018). Pakistan is pursuing the principle of economic dispersion and desires for embracing a comprehensive approach for economic growth and distribution of the dividends of the CPEC project to numerous states as being stakeholders, which will transform this region to be a novel commercial pivot of the contemporary world (Fatima, Baig, \& Ali Shah, 2019). The main reason for the importance of CPEC should be based on three fundamental dynamics. The first is to connect the land-locked countries through Gwadar port to the maritime trade routes, which can be attractive and beneficial for adjoining states like the Central Asian region itself, known as the link between the continents (Hussain, 2020). Secondly, two major world powers like Russia and China have an existence closer to Central Asia, which is an attraction for other countries. Thirdly, it is essential due to the availability of extensive energy resources and other commercial benefits (Jiang, 2015).

CPEC, as an economic collaboration of China and Pakistan, will ultimately enhance commercial associations between countries of South Asia and other states like Japan, New Zealand Australia, South Korea, CARs, and ASEAN nations (Fatima, Baig, \& Ali Shah, 2019). Geopolitics and geoeconomics in the region of South-Asian countries have been correspondingly evolving, which being a paradox subsequently not to co-exist together and both are conjointly exclusive (Siddiqi, 2018). CPEC venture will be advantageous for Pakistan and China and will be partaking in progressive economic prospects for India, Afghanistan, Iran, CARs, and the entire region (Fatima, Baig, \& Ali Shah, 2019). The new players of the "New Great Game" have been trying to achieve their objectives of national interests and in the regions of South and Central Asia (Javaid, 2016). More than 51 nations comprising Malaysia, Russia, and Turkey have also planned for joining CPEC (Fatima, Baig, \& Ali Shah, 2019).

The emergence of China as a strategic and economic actor in the region will redesign opportunities for interconnectivity in Asia (Hussain, 2020). Beijing represents a new sense of political wisdom for undertaking initiatives related to connectivity in the region, supported by the surplus capital of the country as a transformation that has altered the environment of security in the neighbourhood of India (Baruah, 2018). China will make available prospects to minimize dynamics of geopolitical antagonism using CPEC to be considered significant concerning Pakistan and India for resolution of their bilateral disputes at the cost of economic gains (Siddiqi, 2018). Central Asia has massive natural resources of hydrocarbon reserves (Jiang, 2015), which may be accessible through CPEC (Jia, 2017).

\section{RESEARCH METHODOLOGY}

The study is qualitative and explanatory. The importance of CPEC as an economic driver was assessed by data analysis contributing to peace in South Asia through economic interdependence. During the investigation, the role and participation of international players as regional players, including China, Pakistan, India, Kashmir, and all parties' reactions were examined. During the current investigation, the available secondary material was searched and retrieved. Data related to newspaper editorials, websites, research articles, and journals have been collected and scrutinized.

\section{RESULTS AND DISCUSSIONS}

Geopolitical disputes have become a major cause of minimum economic interactions between hostile states, consequently meaning that geopolitics endures being of prominence (Siddiqi, 2018). Significant marine trading routes have passed through the IOR, carrying about 50 percent of international trade. The financial interests of the dominant world economies necessitate the establishment of tranquillity and peace in the region (Humayun, 2018). The development and sustenance of Pakistan, India, and Afghanistan are dependent on a sound economic footing for the attainment of apparent commercial advantages using bilateral and multilateral connections. With the persistence of conflicts and tensions in the region of South Asia, a materialization of the economic benefits concerning CPEC may turn out to be a distinct probability with time (Siddiqi, 2018).

\section{Impact of CPEC on Kashmir}

Kashmir has geostrategic significance for China, Pakistan, and India. Kashmir valley is a primary source of water needs of Pakistan for irrigation of the fertile grasslands of Punjab. The Indus River and its tributary waterways originate from Kashmir, being the prime sources of freshwaters in Pakistan. The controlling of water flow in the tributaries through canals and dams has prevailed to be a core issue amid Pakistan and India for decades (Wani, 2017). Kashmiris are lynching for 73 years as a territorial dispute between India and Pakistan. They have paid high human costs for the implementation of the UNSC resolutions. The devised rights of human beings and philanthropic bylaws vis-à-vis resolutions of the UNSC have substantiated to be frail to establish positive peace in the region of South Asia and balance power in the Indian subcontinent (Rasool \& Kundi, 2018). In the recent past, the Kashmir Valley was considered to be 
connected to the ancient "Silk Route" passing through the area of Ladakh and Gurez (Bandipur). By doing so, CPEC would be capable of providing enormous prospects for enhancing the economic interaction of Kashmir to the countries of the Middle East, CARs, European states, and West Asian nations. The use of railways, highways, oil and gas pipelines, and power transmission lines through regional interaction must have the potential to reap the benefits of CPEC, resulting in increased trade activities, increased trade links. Improving technical cooperation, creating a generation, creating modern economic opportunities, and promoting social and cultural ties between the people will help in the socio-economic development of the Kashmir Valley. The economy of Kashmir will be linked to the world markets as well as it could get access to big market economies for the supply of commodities and soon would turn out to be an extensive transit trade zone of the region (Wani, 2017). Implementing this broader strategic and economic plan will usher in a social and economic revolution in the area that could change the fortunes of the Kashmir Valley (Rasool \& Kundi, 2018). CPEC will possess a more significant financial worth by providing enormous commercial and trade opportunities to all stakeholders connected to make South Asia a flawless unified region of the world (年bal, 2018).

CPEC will exert a regulating impact on the Pak-India relationship and Kashmir conflict (Rasool \& Kundi, 2018). Geographically, the valley of Jammu and Kashmir is located in adjacent contiguity to the CPEC venture. To attain advantages while connected under CPEC, China, Pakistan, and India conjointly will have to overlook geoeconomics as an actor of peace, which may lead to resolution of the Kashmir dispute and other prevailing conflicts between Pakistan and India (Wani, 2017). CPEC will transfigure the geographic position of Azad Jammu and Kashmir into an asset to be an economic engine for the establishment of peace in the region (Iqbal, 2018). Although, the valley of Kashmir is a landlocked area with no admittance to the outer world excluding the single Srinagar to Jammu region interlinking route, which may have utterly comparative benefits associated with India's participation in CPEC (Wani, 2017).

CPEC has been projected to regulate dialogue on Kashmir disputes from extraordinary areas of higher politics like survival, sovereignty, and territory towards lower areas of politics being social and economic affairs (Iqbal, 2018). CPEC will bring economic prosperity to Pakistan, converting it into a stable country that may have to be perceived in the Indian favour. It would mark a new chapter for the establishment of peace and prosperity, mainly in South Asia and predominantly in the continent of Asia (Wani, 2017). Being the gateway to the CARs, Jammu and Kashmir will become a hub for trade activities in the region. The LOC can reap huge benefits from economic efforts that will bring political stability to the area. Instead, we will intensify it. Along with the peace of the local people, it will create an area to be a hub for the evolution of trade potentials moving towards cooperation in trade, tourism, industry, and economic projects. (Rasool \& Kundi, 2018). The initiation of more trading routes and interlinking of FEZ alongside the LOC will entirely change the trade and economic structure of the Jammu and Kashmir valley, leading towards the prosperity of people to a large extent in the region and hoping for a better future for the generations of Jammu and Kashmir (Wani, 2017).

The regional connectivity will bridge the economic gap while maintaining equilibrium may impact the Kashmir conflict (Rasool \& Kundi, 2018). The battles and wars can be fought based on technical and socio-economic cooperation of common interests between the enemy states across the border (Iqbal, 2018), which can be nurtured if accompanied by civilian, military, and political elites as related segments. Population agrees that trade aid can have tangible benefits outside and within regional domains (Wani, 2017). China's resolution of conflict model contemplates "low-politics" as one of the most comprehensive approaches towards mutual relationship and management of disputes. The constant engagement in commercial trade, people-to-people interaction, environmental security, and food drives towards creating a conducive environment for initiation of meaningful negotiations by constructive approach concerning the issues of high politics (龟bal, 2018).

CPEC identifies the novel regional and global inevitabilities of politics by cultivating a systematically improved and needs centered collaboration for trade and industrial development and socio-economic growth based on connectivity (Wani, 2017). CPEC can promote economic cooperation and interdependence in the region to facilitate the resolution of the Kashmir dispute between Pakistan and India and turn away from zero-sum methodologies of the regional conflicts (Iqbal, 2018). In the evolving dynamics of South Asia, economic cooperation under CPEC amid Pakistan and India is very substantial for China and the resolution of the Kashmir dispute, which will have the capacity to upset the environment of regional peace and security. China emphasizes peaceful resolution of the Kashmir issue based on interests associated with Pakistan, the Azad Kashmir region, and India (Haider Bukhari \& Parveen, 2014). CPEC may also pave the ways for the amicable resolution of prolonged Kashmir disputes using economic connectivity (Iqbal, 2018).

China has become emergent power in Asia, which is going to portray its image as being a soft power of the world. It has been establishing a friendly relationship with the neighbouring and other countries based on mutual respect for all noninterference in the domestic affairs of other states (Rasool \& Kundi, 2018). In the regional framework of South Asia, China and India have battled over a territorial dispute in the past. At the beginning of the $21^{\text {st }}$ century, a significant paradigm shift has been observed in Indo-China cooperation regarding mutual trade and economic relations. Both India and China planned to immensely enhance their commercial and economic prospects, irrespective of their differences (Jia, 2017). The policymakers of both countries realized the significance of trade for being a crucial indicator for the growth of the economy, on accounts of which the volume of Indo-China bilateral trade reached US\$100 million in 2015 (Haider Bukhari \& Parveen, 2014). Pakistan and India may find a solution to their unresolved disputes using 
negotiations to establish peace in the region. For harmonization of the idea by Pakistan and India, CPEC may be extended towards India by the auxiliary interlinks from parts of Punjab and valley of Kashmir to turn out the suspicious threats of reciprocal security to mutual economic advantages like; 1) Kashmir will be connected to the world economic markets of its commodities which may have benefits concerning the supply of dry fruits and apples; 2) The tourist industry of Kashmir will flourish to the extent that it can enhance the reserves of FDI as well as could also benefit the economy of Kashmir to the levels gross root; 3) With the growth of the economy and commercial activities, there will be job opportunities to the unemployed people both from inside and out of the Kashmir valley; 4) The CBMs like people to people will establish peace and tranquillity in the region; 5) It will result into the growth and development of the economy of Kashmir to a large extent (Wani, 2017). To share the dividends of OBOR, Pakistan, China and India should adopt the win-win approach. The spillovers may play a crucial role in a peaceful solution to the long-lasting conflict of Jammu and Kashmir between Pakistan and India (Akhtar, Hussain, Nawaz, \& Haider, 2021).

\section{Imperatives of CPEC for India}

The dynamics of the regional geopolitics will be converted into a novel form in the perspective of whether India joins CPEC or discovers ways for interconnectivity of the IHK valley to the economical conduit of the region (Iqbal, 2018). CPEC will lead towards accumulative engagement of people of Kashmir amongst both sides of LOC, and it will also help for interconnection of people using the commercial interests, thus paving the way for resolution of the longstanding conflict of Kashmir through peaceful means (Rasool \& Kundi, 2018). It (CPEC) may provide new impetus for the energy and technology of India to the nations of CARs and respond to the emergent influence of Beijing in the region (Wani, 2017).

India could also take the material advantages of accessing the CARs through CPEC (Naseer, 2017). India will appear in the region's political environment as an imperative player and trying to secure foot-holding and enhancement of influence in Central Asia (Jiang, 2015). As Asia's third-fastest and largest growing economy, energy security is crucial in India's plan to move into CPEC and connect its ports to Central Asia via pipelines (Usman, 2020). India could reap huge benefits by joining the CPEC project and opening new trade centres via Pakistan. New Delhi seeks access to CARs and Afghanistan to expand its entry into regional economic markets. And to achieve that. (TAPI) Turkmenistan-AfghanistanPakistan-India gas pipeline dream come true. However, as two strategic key actors in the South Asian region based on hostility and long-standing mistrust, Pakistan and India have been reluctant to minimize their hostility tactics against each other. (Wani, 2017).

Afghanistan-Pak-India pipeline to expand its influence in the nations of Central Asia and Afghanistan and maintain the practical options and energy supply of the natural gas pipeline from Iran and Oman to the Indian Ocean are India's critical objectives in the region (Shoukat, 2015). For this purpose, peaceable Afghanistan may be significant for futuristic improvements in the area. The project of Turkmenistan, Iran, India, and Pakistan gas pipeline and its conclusion is reliant on security conditions in Afghanistan, on accounts of which India may have political and economic leverage in the region (Jiang, 2015). CPEC will have the potentiality for the incarnation to the culmination of the pipeline of gas (IPI) Iran-Pak-India to accomplish requirements of energy demands of New Delhi. It is a crucial time for India to decide about joining CPEC to enhance commercial and economic benefits. Otherwise, the role of New Delhi may disappear concerning economic connectivity at the regional levels in the forthcoming milieu (Wani, 2017).

\section{Recommendations}

1) CPEC shall be extended via Kunjrab to Neelam Valley up to Chakotti along the line of control that connects Srinagar Rawalpindi Road. It will enforce the cease-fire of 2004 and secure the areas under Indian fire vis-à-vis will uplift Azad Jammu and Kashmir people comically with a sense of security (Iqbal, 2018).

2) Gilgit Baltistan and Azad Jammu and Kashmir may be declared free economic zone as CPEC passes through GB (Akhtar, Hussain, Nawaz, \& Haider, 2021).

3) Pakistan and China in the region can ponder upon in later stage to declare the whole state of Jammu and Kashmir as a free economic zone when Azad Jammu and Kashmir will be economically stable (Rasool \& Kundi, 2018).

\section{CONCLUSION}

It is imperative to conclude that the two emerging economies, China and Pakistan, conjointly have endeavoured to formulate an "Economic-Corridor" known to be CPEC to accomplish their economic objectives for mutual growth and development. It is the mega driver of Globalization and an instrument of soft balancing and can bring economic equilibrium through development and interconnectivity. CPEC is well-thought-out to be an effective catalyst for establishing peace in the South Asian region and may be advantageous for all. It will offer tri-lateral advantages to India, China, and Pakistan, which testifies the framework of International Economic Leverage.

CPEC is perceived to be the Marshall-Plan version of Beijing in the region. The China-Pakistan Economic Corridor will provide grounds for minimizing conflicts on accounts of consistent regional and intra-regional economic connectivity in South Asia. CPEC will transfigure the geographic position of Azad Jammu and Kashmir into an asset to be an economic engine for the establishment of peace in the region. It will be a mega Kashmir centric CBM and a significant catalyst of 
conflict resolution and establishment of peace in the area. CPEC may also pave the way for the amicable resolution of the prolonged Kashmir dispute through economic connectivity. CPEC is viewed as a win-win for India, Pakistan, and China, and the whole region.

\section{LIMITATIONS OF THE STUDY}

The research is limited to analyze that CPEC is a significant economic actor which can be utilized for the establishment of peace and prosperity in the region through economic gains and mutual interdependence. The research suggests a viable solution for the peaceful resolution of the Kashmir issue between Pakistan and India.

\section{ACKNOWLEDGEMENT}

I declare that there is no conflict/s of interest associated with this publication, and there has been no financial support for this work that could have influenced its outcome.

\section{AUTHOR'S CONTRIBUTION}

Fakhar Hussain, Sarfraz Husain: Devised the main idea and wrote the paper.

Muhammad Ikramullah Khan: Arrangement of the data.

Sarfraz Hussain: Framed research design and edited the manuscript.

Saadat Nawaz: Arrangement of the data.

\section{REFERENCES}

1. Akhtar, D., Hussain, F., Nawaz, S., and Haider, S. (2021). "An Analysis of Pak-India Rivalry over Kashmir Dispute: A Conflict Resolution Approach." Elementary Education Online, 20(3),1979-1986.

2. Ali, S., and Saeed, P. (2019). "Kashmir Dispute and Challenges to the National Security of Pakistan: An Analysis." Electronic Research Journal of Social Sciences and Humanities, 1(II), 61-77.

3. Baruah, D. (2018). India's Answer to the Belt and Road: A Road Map for South Asia. Retrieved from Carnegie Endowment for International Peace: http://carnegieEndowment.org.

4. Bhattacharjee, D. (2015, May 12). China Pakistan Economic Corridor (CPEC). Retrieved from Indian Council of World Affairs. https://doi.org/10.2139/ssrn.2608927

5. Dhall, D. (2018). Strategic Importance of Kashmir: A Conflict between India and Pakistan. Journal of Advances and Scholarly Researches in Allied Education, XIV(2), 192-199.

6. Durrani, S., Bilal, M., and Kalim, I. (2017). Pakistan-China Strategic Partnership: Capitalizing the Geopolitical Location of Pakistan. Global Regional Review (GRR), 2(1), 152-165. https://doi.org/10.31703/grr.2017(II-I).11

7. Fatima, N., Baig, A., and Ali Shah, B. (2019). China-Pakistan Economic Corridor (CPEC): Fostering the Trade, Investment and Economic Globalization. Global Social Sciences Review (GSSR), IV(II), 283-290. https://doi.org/10.31703/gssr.2019(IV-II).37

8. Haider Bukhari, S., and Parveen, M. (2014). China's Approach Towards Kashmir Conflict: A Viable Solution. Journal of Professional Research in Social Sciences, 1(1), 14-30.

9. Humayun, A. (2018). Pakistan's Vision of Maritime Security and CPEC: Thought Piece. Changing Security Situation in South Asia and Development of CPEC (pp. 53-60). Islamabad: Islamabad Policy Research Institute (IPRI).

10. Hussain, F. (2020). Geostrategic Imperatives of Gwadar Port for China. The Korean Journal of International Studies, 18(2), 145-167. https://doi.org/10.14731/kjis.2020.08.18.2.145

11. Hussain, F., and Hussain, D. (2017). China-pak economic corridor (cpec) and its geopolitical paradigms. IJSSHE-International Journal of Social Sciences, Humanities and Education, 1(2), 79-95.

12. Hussain, F., Ahmad, D., Nawaz, S., Haider, S., and Atif, M. (2021). Challenges to China-Pak Economic Corridor (CPEC): The Indian Perspective. Elementary Education Online, 20(5), 3764-3770.

13. Hussain, F., Hussain, S., Ahmad, N., Quddus, A., Rafiq, M., and Tien, P. (2021). China-Pak Strategic Entente With Respect To Search For Reciprocated Security Through Gwadar Port. Psychology and education, 58(1), 3320-3333. https://doi.org/10.17762/pae.v58i1.1271

14. Hussain, F., Khan, M., Hussain, S., Nawaz, S., and Ahmad, N. (2021). Dynamics of Regional Geopolitics and Challenges to CPEC: The Afghan and Iranian Perspectives. Elementary Education Online, 20(5), 3235-3243.

15. Hussain, S., Hassan, A., Rafiq, M., and Quddus, A. (2019). The Impact of Exchange Rate Exposure and Working Capital on Return on Equity. International Journal of Disaster Recovery and Business Continuity 10(December), 64-74.

16. Hussain, S., Rafiq, M., Ahmad, N., Quddus, A., and Tien, P. (2021). Pak Rupee As A Currency And Currency War. Journal of Contemporary Issues in Business and Government, 27(1), 889.

17. Hussain, S., Rafiq, M., Quddus, A., Ahmad, N., and Tien , P. (2021). China-Pakistan Economic Corridor: Cooperate Investment Development And Economic Modernization Encouragement. Journal of Contemporary Issues in Business and Government, 27(1), 96-108. 
18. Iqbal, D. (2018). CPEC: A Corridor for Minimizing Political Fault lines in South Asia. Changing Security Situation in South Asia and Development of CPEC (pp. 91-111). Islamabad: Islamabad Policy Research Institute (IPRI).

19. Javaid, U. (2016). Assessing CPEC: Potential Threats and Prospects.. JRSP, 53(2), 254-269.

20. Jia, C. (2017). New Trends of US Policy toward South Asia: Challenges to CPEC. IPRI Journal, XVII (1), 95121.

21. Jiang, L. (2015). India's attitude toward CPEC and China's countermeasure. Retrieved February 20, 2021, from GC University Lahore: http://www.ps.gcu.edu.pk/iccpec/

22. Markey, D., and West, J. (2016). Behind China's Gambit in Pakistan. Retrieved March 31, 2021, from http://www.cfr.org: http://www.cfr.org/pakistan/behind-chinas-gambit-pakistan/p37855

23. Naseer, S. (2017). CPEC: Past and Future Challenges. Retrieved March 31, 2021, from Spearhead Research: http://www.spearheadresearch.org

24. Rasool, S., and Kundi, M. (2018). CPEC, the driver of globalization and positive peace: an Inquiry through Kashmir dispute. The pakistan journal of social issues, Special Issue June, 28-36.

25. Rifaat, H., and Maini, T. (2016). The China-Pakistan Economic Corridor Strategic Rationales, External Perspectives, and Challenges to Effective Implementation. Retrieved from Stimson Centre: http://www.stimson.org

26. Shoukat, A. (2015). Importance and Implications of CPEC in South Asia: The Indian Factor. Journal of Indian Studies, 1(1), 21-36.

27. Siddiqi, F. (2018). CPEC and Geo-Politico-Economic Trends of the Region: An Appraisal. Changing Security Situation in South Asia and Development of CPEC (pp. 25-44). Islamabad: Islamabad Policy Research Institute (IPRI).

28. Usman, M. (2020). Iran-Pakistan Relation: Impact on CPEC. Asian Journal of Social Science and Management Technology, 2(3), 53-60.

29. Wani, M. (2017, March 19). CPEC and Kashmir: A study in the context of geoeconomics perspective. Retrieved from The Daily Greater Kashmir: https://www.researchgate.net/publicatio n/325659474 1CPEC_AND KASHMIR 1932017-md-hr-9? enrichId=rgreq-48c979a0cb70b1ff9d6b3a6e5fd0e 71f-XXXandenrichSource=Y292ZXJQYWdlOzMyNTY1OTQ3NDtBUzo2MzU1Nzk2NDk3NjEyODFAM TUyOD UONTQwNTA2NA\%3D\%3Dandel=1_x_2and_esc=publicationCov.

30. Wellens, K. (1990). Resolutions and Statements of the United Nations Security Council:(1946-1989). A Thematic Guide. Brill. 